\title{
Cost benefit analysis for failure of sewer pipelines
}

\author{
Mohamed Elmasry ${ }^{1, *}$, Alaa Hawari ${ }^{1}$, and Tarek Zayed ${ }^{2}$ \\ ${ }^{1}$ Dept. of Civil and Architectural Engineering, Qatar University, P.O. Box 2713, Doha, Qatar \\ ${ }^{2}$ Dept. of Building, Civil and Environmental Engineering, Concordia University, Quebec, Canada
}

\begin{abstract}
Sewer pipelines failure in sewage networks can have adverse potential impacts on socio-economic aspects in any community. Due to the fact that it's difficult to capture the relationship between the physical and economical aspects as a result of critical sewer pipelines failure, economic concepts are used to evaluate the economic loss as a result of these failures. In this paper an analysis for the costs resulting from sewer pipelines failure and the benefits achieved from avoiding failures are presented. The costs included in the cost benefit analysis are the direct costs used to reinstate failed pipelines and the indirect costs, borne by the society and economy. In the benefits analysis, only the tangible and measurable benefits limited to the health sector and preventing diseases are addressed in this paper. It is expected that the proposed approach could help in estimating the economic losses due to sewer pipelines failure especially for the intangible factors that are difficult to measure. In addition it could help decision makers in taking necessary measures to preserve critical assets that could have adverse potential impacts on valuable natural resources such as surface and groundwater and soil surrounding failed pipelines.
\end{abstract}

\section{Introduction}

The research addressing buried infrastructure in general and sewer pipelines in particular raises the concerns about lack of condition assessment tools, cheap non-destructive inspection technologies, and data for use in risk assessment models[1]. These challenges are considered as impediments to better asset management for which interest has been increasing lately. Consequences of failure of sewer pipelines which is part of risk assessment models could have adverse potential impacts on business and environment. Due to the uncertainty accompanied to estimating the costs of these failures, little research have been conducted to valuate them. Since the end of the 1990s, numerous studies have been carried out with the aim of defining the costs of failure of infrastructures that are not considered direct costs. The studies first agreed to describe costs incurred by owners of underground infrastructure to reinstate the failed assets [2]. Then, started to identify costs that are invoiced as social or indirect costs; borne by the whole society [3-6].

${ }^{*}$ Corresponding author: $\underline{\text { m elmasry@aucegypt.edu }}$ 
To determine the consequences of failure of sewer pipelines, authorities in Seattle in USA developed a risk assessment tool that determines the consequences of failure for sewer pipelines in monetary values [7]. In another study and as a part of Computer Aided Rehabilitation of Sewer and Storm Water Networks (CARE-S) project in Europe, a study was carried out to investigate the social and economic costs of sewer failures [8]. As part of the grand central model developed to determine the societal costs for pipeline failure, traffic valuation as a result of pipeline failures has been addressed by Cromwell and Pearson [9]. Although the grand central model is considered as one of the best efforts to date to estimate the societal costs for pipeline failure, it requires good knowledge of traffic flow and is dependent on many parameters that are hard to identify such as the remaining distance, the type of routes taken, the weather and most of all; the behaviour of commuters. To overcome the difficulties that might accompany estimating the consequence of failure in monetary amounts, another approach was used; in which determining the consequence of failure values was considered as a multi-criteria decision making problem, and different pipes were considered as the alternatives with different factors' weights having different importance levels as the criteria $[10,11]$.

Cost Benefit Analysis (CBA) is a quantitative approach used by economists where monetary and non-monetary aspects can be incorporated in the decision making process. CBA estimates the changes in utility resulting from changes in conditions that customers would face as a result of changes in environmental quality, and/or availability of products and labour. The analysis conducted in CBA is clear in its requirement where different parameters are either categorized in costs or benefits with the goal of maximum utility based on the nature of the problem- is considered the goal. In addition, CBA should show the costs and benefits accruing to different social groups of beneficiaries and nonbeneficiaries. Also, CBA has the ability to express costs and benefits either in monetary units or weighted by an index related to the importance of beneficiary or non-beneficiary groups. Several cost benefit analysis approaches have been addressed in literature to valuate decision in terms of benefits gained in the field of infrastructures and funds allocation [1214]. Approaches such as: benefit cost ratio $[15,16]$ and cost utility $[17,18]$ differing based on the objectives for evaluation of decision alternatives. The objective of this paper is to analyze costs - including direct and indirect ones - resulting from failures of sewer pipelines and the benefits returning on consumers and community as a result of avoiding such failures in an attempt to determine the economic loss as a result of these failures.

\section{Economic loss of infrastructures failure}

Critical infrastructures also known as critical assets are usually identified using a risk based assessment methodology as stated by the American Electric Reliability Corporation [19]. Risk analysis methodologies help in assessing critical infrastructures from which proper assessment management plan can be carried out for these infrastructures. This is usually carried out by performing a what-if scenario for the outcome of the event of failure of infrastructure and assessing the outcome in a qualitative or quantitative manner [20]. Economic loss is defined as the difference between the economic output in a baseline scenario representing the business as usual and the output in a disaster scenario which represents post infrastructure failure. The economic output in the disaster scenario models the consequence of failure of an asset. Estimating the economic loss requires integrating lost output overtime. Therefore the process of estimating the impacts resulting from a disaster starts with analyzing the various hazards, the exposure and vulnerability of physical, social and environmental systems. 


\section{Cost Benefit Analysis (CBA) of sewer pipelines failure}

\subsection{Cost of failure of sewer pipelines}

To determine the consequences of sewer pipeline failures, direct and indirect costs as a result of these failures are estimated. The consequences of failures are then determined based on the total costs, where a pipe has a higher consequence if the total costs of failure are higher than when compared to another pipe with less cost. Total costs of failure can be determined by adding direct costs and societal costs (indirect costs).

\subsubsection{Direct Costs}

The direct costs can be categorized as all costs related to the reconstruction of underground infrastructure. These costs are easily spotted and identified because they correspond mostly costs that are tangible which include costs of materials, resources (equipment and labour) involved in restoration works in addition to management and/or administrative costs [21].

\subsubsection{Indirect Costs}

It is difficult to give an exact definition regarding the indirect costs associated with the failure of an asset in general and sewer pipelines in particular. However, the indirect costs can be arbitrarily defined as costs associated with loss of productivity of other functioning parties and lost wages as a result of failure. The following section describes the cost estimation for different categories of sewer pipelines failure considered in the proposed model.

\section{Costs related to service interruption}

Service outage: Infrastructure failure could have a cascading effect, which means that if a stretch in a network fails, this failure might affect an adjacent stretch in the same network or other utilities. The disruption in these services conveyed by the affected utilities represents a cost to society. The cost can be assigned to the service interruption as per Eq. (1).

$$
\mathbf{C}_{\mathbf{s}}=D * \sum_{i=1}^{N} C_{h} * n
$$

Where: $\mathrm{C}_{\mathrm{s}}$ : Cost of an interruption of service, D: Duration of the interruption (h), $\mathrm{C}_{\mathrm{h}}$ : Average hourly Cost of the service $(\$ / \mathrm{h}), \mathrm{n}$ : the number of affected customers of Type (i) and $\mathrm{N}$ : the number and total number of affected customers.

Emergency interventions: In some cases lives of citizens might be jeopardized as a result of sewer pipelines failure. Thus, emergency interventions such as public services including paramedics or hospital services, police forces and civil defence department might be needed to help threatened lives to ensure safety of publics. The costs related to the use of these resources shall be taken into account as indirect costs even though it's not necessarily present in all cases as per Eq. (2).

$$
\mathbf{C}_{\mathbf{I S}}=\sum_{i=1}^{N} c_{v}^{i} * t_{R}^{i}
$$

Where: $\mathrm{C}_{\mathrm{IS}}$ : Total cost of intervention of public security services, $\mathrm{c}_{\mathrm{v}}^{\mathrm{i}}$ : Hourly rate of vehicle of type (i) $(\$ / h), t_{R}^{i}$ : Repsonse time of vehicle of type (i) (h) and $\mathrm{N}$ is the number of emergency vehicles deployed in the accident.

Costs related to traffic disruption and road closure

Road closure and traffic disruption: Sewer pipelines failure may cause partial or total closure of roadways in the affected zones and might further extend outside the premises of the failure, resulting in numerous costs [22]. 


$$
\mathbf{C}_{\text {Con }}=d * f_{c} * \sum_{i=1}^{N}\left(\operatorname{Con}_{\text {dis }}^{i}-\operatorname{Con}_{n o r}^{i}\right) * \sum_{j=1}^{M} n_{V(i)}^{j}
$$

Where: $\mathrm{C}_{\mathrm{Con}}$ : Cost of overconsumption due to congestion,d: Disruption distance $(\mathrm{km}), \mathrm{f}_{\mathrm{c}}$ : Fuel price (\$/L), $\operatorname{Con}_{\text {dis }}^{\mathrm{i}}$ : Average consumption of vehicles of type (i) during disruption $(\mathrm{L} / \mathrm{km}), \operatorname{Con}_{\text {nor }}^{\mathrm{i}}$ : Average consumption of vehicles of type (i) during normal cases $(\mathrm{L} / \mathrm{km}), \mathrm{n}_{\mathrm{V}(\mathrm{i})}^{\mathrm{j}}$ : Number of vehicles of type (i) impacted per day (j) (Vehicles/day) and $\mathrm{N}$ and M: Total number of vehicles and total number of days, respectively.

Loss of parking spaces: During the restoration of failed sewer pipelines located in the premises of roads in urban areas, it may be important to take into account the aspect of reducing the space on ground which would also affect areas dedicated to car parking [23]. This cost can be calculated as per the model of Pucker et al. [24] as per Eq.(4).

$$
\mathbf{C}_{\mathbf{l p}}=N_{n a} * c_{p} * R_{o} * d * t
$$

Where: $\mathrm{C}_{\mathrm{lp}}$ : Cost of loss of parking spaces, $\mathrm{N}_{\mathrm{na}}$ : Number of non-accessible parking spaces, $c_{p}$ : Hourly cost of parking ( $\left.\$ / h\right), R_{o}$ : Rate of occupancy (\%), d: Length of the reconstruction period (day) and $\mathrm{t}$ : Number of operating hours per day (h / day)

Loss of time as a result of increased traveling distances for vehicles: The most crucial point related to the disruption of traffic in studying failure of sewer pipelines, is the traffic congestion. The loss of time can be calculated using extra time needed to travel the same distance which is the most close to the real time situation allowing quantification of costs of congestion correctly and easily [6].

$$
\mathbf{C}_{\mathbf{T D}}=\sum_{i=1}^{N}\left(n_{v}^{i} * o . r_{v}^{i} * r_{p}^{i}\right) * t * d
$$

Where: $\mathrm{C}_{\mathrm{TD}}$ : Cost of time loss due to traffic diversion, $\mathrm{n}_{\mathrm{v}}^{\mathrm{i}}$ : Number of vehicles of type (i), o. $r_{v}^{i}$ : Occupancy ratio of vehicle of type (i), $r_{p}^{i}$ : Hourly rate of passenger in vehicle of type (i), t: Detour time (h), d: Number of days (days) and $\mathrm{N}$ is the total number of vehicles of type (i)

Loss of time as a result of increased traveling distances for pedestrian: Zhang et al, [25] developed a model to estimate the loss of time in case of pedestrians using the same previous approach as per Eq.(6).

$$
\mathbf{C}_{\mathbf{P D}=} r_{p} * t * n * d
$$

Where: $\mathrm{C}_{\mathrm{PD}}$ : Cost of lost time due to the detour for pedestrians, $\mathrm{r}_{\mathrm{p}}$ : Average hourly rate of a pedestrian $(\$ / h)$, t: Detour time (h), n: Number of pedestrians per day and d: Number of days (Days)

Increased running costs for vehicles: Traffic congestion causes an increase in vehicle operating costs due to utilizing detours which would consequently cause an increase in vehicles' running costs [6]. Thus, it is possible depending on the speed and type of vehicles to establish an average maintenance cost per kilometre that is considered as a cost of the road network disruption [22].

$$
\mathbf{C}_{\mathrm{dis}}=\sum_{i=1}^{N} c_{v}^{i} * \sum_{j=1}^{M} n_{v}^{j} * d
$$

Where: $\mathrm{C}_{\mathrm{dis}}$ : Additional cost due to additional distance, d: Additional distance, $\mathrm{c}_{\mathrm{v}}^{\mathrm{i}}$ : Running cost per Kilometer for vehicle of type (i) $(\$ / \mathrm{km}), \mathrm{n}_{\mathrm{v}}^{\mathrm{j}}$ : Number of vehicles of type (i) impacted per day (j) (Vehicles/day) and $\mathrm{N}$ and $\mathrm{M}$, are the total number of vehicles of different types and the total number of days spent in restoration works respectively. Costs related to environmental impacts

The environmental impact of a failed sewer pipelines could be during the event of failure and during reinstatement of the failed asset. Although the disturbances might not have visible impacts, many of these disturbances might be costly and irreversible. The flooding of failed sewer pipes affects the surface and ground water quality and soil in which the waste effluent is discharged. Wastewater discharged due to flooding or leakage in sewage pipelines to water bodies and soil surrounding these pipes could have adverse health issues and complications. Medical costs could be generated despite all precautionary 
measures that could be made, because of the diseases or infections that increase the health care costs [4]. To calculate the volume of contaminated groundwater and/or soil, the advancement of plume is calculated using dispersion equations. The rate of advancement of contaminant plume can be retarded if there is a reaction between its components and groundwater constituents as per Eq. (8) [26].

$$
\mathbf{R}=1+\frac{\gamma_{b}}{\varepsilon} * k_{d}
$$

Where: $\mathrm{k}_{\mathrm{d}}=\beta \mathrm{fk}_{\mathrm{ow}}, \mathrm{f}=0.01$ in sandy soil to 0.10 in muck, $\beta=0.41$ and $\mathrm{k}_{\mathrm{ow}}$ : is a constant.

The effluent that leaks from broken sewer pipelines are usually untreated raw sewage that seeps to groundwater and soil surrounding the location of failure. This can result in introduction of chemicals such as nitrates phosphates, and microorganisms [27]. To determine the concentration of chemicals intrusion from which volume of contaminated soil and/or groundwater can be estimated. Eq.(9) can be used to calculate the maximum concentration just downstream the contaminant source using parameters related to the medium in which it is desposed [26].

$$
\mathbf{C}_{\max }=\frac{M}{8 * \text { porosity } *\left(\frac{\pi t}{R}\right)^{3 / 2} * \sqrt{D_{x} D_{y} D_{z}}}
$$

Where, $\mathrm{D}_{\mathrm{X}}=$ Bulk velocity $*$ diameter of soil particles and $\mathrm{D}_{\mathrm{y}}=\mathrm{D}_{\mathrm{z}}=0.1 * \mathrm{D}_{\mathrm{x}}$ and the spread of contaminant can be determined using Eq. (10) and (11) [26].

$$
\begin{aligned}
\mathbf{4} \boldsymbol{\sigma}_{\mathbf{x}} & =\frac{4 * \sqrt{2 * D_{x} t / R}}{3} \\
\mathbf{4} \boldsymbol{\sigma}_{\mathbf{y}} & =\frac{4 * \sqrt{2 * D_{y} t / R}}{3}
\end{aligned}
$$

Costs related to economic impacts: General activity of businesses and/or industries is often impacted by asset failures and disturbances which can then be reflected on the economy in terms of reduced productivity, and delays to work.

Reduced productivity: When shops or businesses are affected by failure of an asset, employees' productivity is affected consequently. Gilchrist and Allouche, [4] developed a model to estimate the cost as a result of decreased productivity as a result of noise in a work place as shown in Eq. (12).

$$
\mathbf{C}_{\mathbf{n w}}=T * \sum_{i=1}^{N}\left(F * r_{h} * n\right)
$$

Where: $\mathrm{C}_{\mathrm{nw}}$ : Cost of noise pollution in the workplace, $\mathrm{T}$ : duration of the project (hours), $\mathrm{F}$ : Reduction factor for worker (i), $r_{h}$ : Average hourly rate of worker (i) $(\$ / h), n$ : number of workers affected and N: number of types of workers affected.

Delays and absences from work: Lost productivity can be related to health disorders, and psychological disorders that can be linked to the failure and restoration works of an asset. Eq.(13), estimates the cost of absences from work as a result of restoration works.

$$
\mathbf{C}_{\mathbf{a}}=\sum_{i=1}^{N}\left(r_{h}^{i} * n_{i} * t\right)
$$

Where: $\mathrm{C}_{\mathrm{a}}$ : Cost of absence from work, $\mathrm{r}_{\mathrm{h}}^{\mathrm{i}}$ :Hourly rate of employee of type (i) (\$/hour), $\mathrm{n}_{\mathrm{i}}$ : Number of employees of type (i), t: Time away from work by employee of type (i) (hours) and $\mathrm{N}$ : is the number of total employees of different types

\subsection{Benefits from avoiding failure of sewer pipelines}

The impacts as a result of sewer pipelines failure can be described as increased disease burden due to contaminated surface and ground water bodies that could lead to an increase in illness rates in areas that suffer from waste water contamination. The increased disease burden can result in medical expenditures spent on treatment, indirect costs resulting from illness, which includes the cost of time lost from work, decreased human productivity, and premature deaths and disabilities. As such, the costs paid by patients seeking health care and increased running costs could increase the costs paid by the society for that purpose. As per a study done by World Human Organization [28], the benefits from proper sanitation 
would be avoiding diarrheal diseases that would result in direct economic benefits. Table 1 shows the different variables included when studying how would the health sector and patients benefit from avoiding the failure of assets and consequent contamination of wastewater.

\section{Cost benefit analysis}

An economic cost benefit analysis is crucially important for effective resource allocation to evaluate the economic costs of interventions and the resulting benefits especially when there are many criteria to determine where these resources need to be allocated such as social and environmental considerations. Although it may appear that estimating the benefits resulting on consumers from the improved health or wastewater network is impossible, there are factors that can be measured which would result in the improvement of these services. Cost benefit analysis aims to better understand the social and economic wellbeing in communities after restoration or upgrading failed pipelines. The procedure for a CBA usually comprise determining costs and benefits, quantifying the non-market impact, including indirect costs and calculation of economic performance indicators (i.e. Economic Net Present Value (ENPV), Internal Rate of Return (IRR),...etc.) which is usually done by analyzing macro-economic and social conditions in a community. Eq. (14) shows the $(\mathrm{B} / \mathrm{C})$ formula used in the cost benefit analysis adopted in this research.

$$
\mathbf{B} / \mathbf{C}=\frac{\sum_{t=1}^{T} \frac{B_{t}}{(1+r)^{t}}}{\sum_{t=1}^{T} \frac{C_{t}}{(1+r)^{t}}}
$$

Where $\mathrm{T}$ : is the total number of years of the study period, $\mathrm{B}_{\mathrm{t}}$ : is the benefits per year (Values of harm avoided each year) and $C_{t}$ : is the total costs paid

Table 1.Variables included in estimating benefits from avoiding sewer pipelines failure.

\begin{tabular}{|c|c|c|c|}
\hline & Beneficiary & Variable & Value \\
\hline \multirow{7}{*}{ 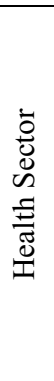 } & \multirow{7}{*}{$\begin{array}{l}\text { Expenditures } \\
\text { saved, due to } \\
\text { less } \\
\text { illness }\end{array}$} & \multirow{2}{*}{ Unit cost per treatment } & Cost per visit (US\$7) [28] \\
\hline & & & Cost per day (US\$28) [28] \\
\hline & & Number of cases & Variable by region \\
\hline & & \multirow{2}{*}{ Visits or days per case } & 1 Outpatient visit per case [28] \\
\hline & & & 5 Days for hospitalized cases [28] \\
\hline & & \multirow{2}{*}{ Hospitalization rate } & $92 \%$ of cases ambulatory $[28]$ \\
\hline & & & $8 \%$ of cases hospitalized [28] \\
\hline \multirow{7}{*}{ 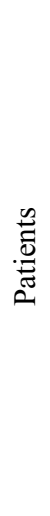 } & \multirow{3}{*}{$\begin{array}{c}\text { Expenditures } \\
\text { saved due to } \\
\text { less } \\
\text { illness }\end{array}$} & Transport cost per visit & Variable by region \\
\hline & & Number of cases & Variable by region \\
\hline & & \multicolumn{2}{|c|}{ Expenditures saved, due to less illness } \\
\hline & \multirow{3}{*}{$\begin{array}{c}\text { Money saved } \\
\text { by avoiding } \\
\text { days lost from } \\
\text { work }\end{array}$} & Days off work & 2 days $(1-4)[28]$ \\
\hline & & $\begin{array}{c}\text { Number of people of } \\
\text { working age }\end{array}$ & Variable by region \\
\hline & & $\begin{array}{l}\text { Cost of } \\
\text { time }\end{array}$ & Minimum wage rate [28] \\
\hline & \multicolumn{3}{|c|}{$\begin{array}{l}\text { Value of loss of life } \\
\text { avoided (life expectancy) }\end{array}$} \\
\hline
\end{tabular}




\section{Case study}

To determine the applicability of the previously proposed equations to determine direct and indirect costs, an actual case study with real data is used for a sewer pipeline located in Monteal city in Quebec, Canada. Table 2 shows the relevant data that were used in calculating the costs. The case study comprises a $200 \mathrm{~mm}$ - vitrified clay pipe with a total length of 60 meters.

Figure 1 shows the different indirect costs, where the groundwater and soil remediation costs represented almost $60 \%$ of the total indirect costs. Figure 2 shows the ratio between direct and indirect costs as a result of the sewer pipeline failure, it can be seen that the values of indirect costs are almost equal the direct costs indicating that they can't be neglected and that they are as important as direct costs.

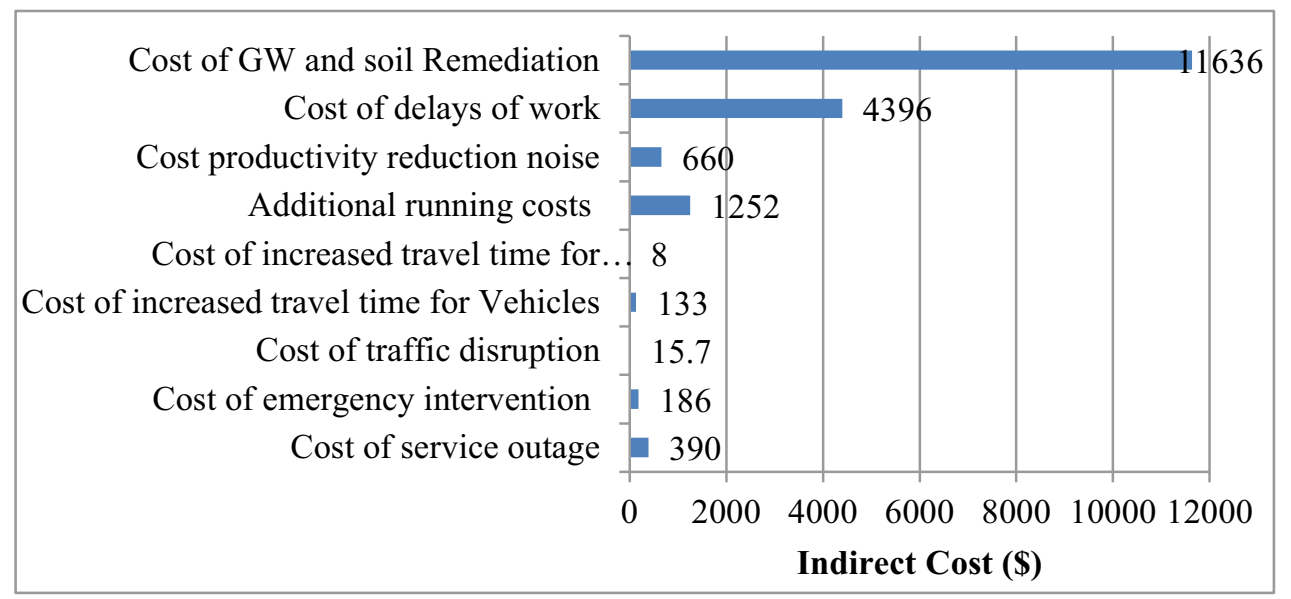

Fig. 1. Indirect Costs for Applied Case Study.

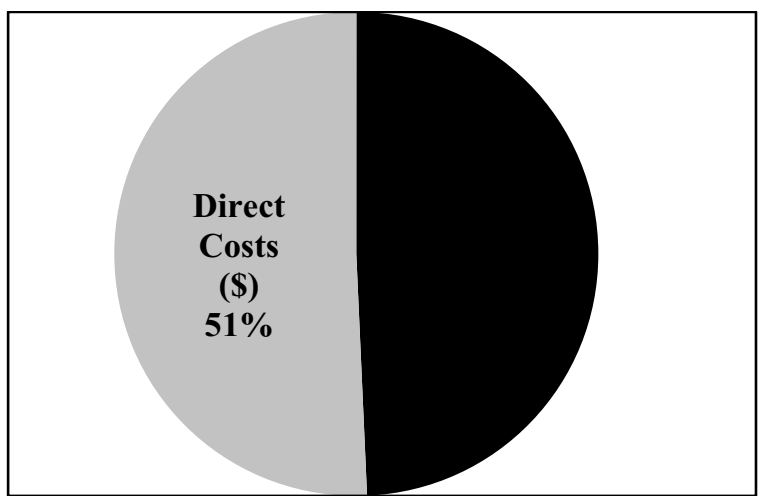

Fig. 2. Direct and Indirect Costs Ratios for Applied Case Study.

To determine the benefits as a result of proper sanitary service, Table 3 shows the different benefits and cost saved as a result of better sanitary service as a result of avoiding failure of sewer pipelines. It should be noted that these costs could be considered as Quality Adjusted Life Years (QALYs) which represents the marginal utility for customers in case of better quality sanitation.

By applying Eq. (15) with study period of one year, the benefit to cost ratio resulted in a value of $\frac{26340}{37882}=0.7$, which indicates that the costs borne by the society as a result of failure would be more than the benefits. In other words the 0.7 ratio indicates that the failure of 
sewer pipeline is catastrophic and more significant than other pipes that would have a ratio greater than 1 .

Table 2. Parameter values used in application of case study.

\begin{tabular}{|c|c|c|c|}
\hline Parameter & \multicolumn{3}{|c|}{ Value } \\
\hline Duration of outage (hours) & \multicolumn{3}{|c|}{72} \\
\hline Cost of service $(\$ / \mathrm{hr})$ & \multicolumn{3}{|c|}{0.028} \\
\hline Number of customers affected & \multicolumn{3}{|c|}{195} \\
\hline Cost of emergency vehicle & \multicolumn{3}{|c|}{62} \\
\hline Number of emergency vehicles & \multicolumn{3}{|c|}{3} \\
\hline Disrupted distance $(\mathrm{km})$ & \multicolumn{3}{|c|}{1.77} \\
\hline Fuel price $(\$ / \text { Litre })^{*}$ & 1.07 & 1.01 & 1.01 \\
\hline Average consumption of vehicle in disruption $(\mathrm{L} / \mathrm{Km})^{*}[29]$ & 0.15 & 0.42 & 0.50 \\
\hline Average consumption of vehicle in normal cases $(\mathrm{L} / \mathrm{Km}) *[29]$ & 0.1 & 0.28 & 0.33 \\
\hline Number of vehicles impacted (Vehicles/day)*[29] & 567 & 13 & 9 \\
\hline Number of inaccessible parking spaces & \multicolumn{3}{|c|}{0} \\
\hline Hourly cost of parking $(\$ / \mathrm{hr})$ & \multicolumn{3}{|c|}{4} \\
\hline Occupancy ratio $(\%)[29]$ & \multicolumn{3}{|c|}{1.63} \\
\hline Number of operation hours for parking lot (hr/day) & \multicolumn{3}{|c|}{24} \\
\hline Hourly rate of passengers $(\$ / \mathrm{hr})[29]$ & \multicolumn{3}{|c|}{11} \\
\hline Detour time $(\mathrm{h})$ & \multicolumn{3}{|c|}{0.0042} \\
\hline Number of pedestrians affected [29] & \multicolumn{3}{|c|}{57} \\
\hline Running cost per kilometer for vehicle $(\$ / \mathrm{km})^{*}$ & 0.7 & 0.8 & 1.1 \\
\hline Number of workers affected in work place & \multicolumn{3}{|c|}{17} \\
\hline hourly rate for workers in work place $(\$ / \mathrm{hr})$ & \multicolumn{3}{|c|}{11} \\
\hline F reduction factor & \multicolumn{3}{|c|}{0.05} \\
\hline
\end{tabular}

*Values represent different types of vehicles namely light, medium and heavy

Table 3. Parameter values used in calculating benefits of avoiding sewer pipeline failures.

\begin{tabular}{|l|c|}
\hline \multicolumn{1}{|c|}{ Parameter } & Value \\
\hline Number of customers affected & 195 \\
\hline Number of probable infections (14\%)[28] & 27 \\
\hline $92 \%$ for 1 day (7\$/day) & 175 \\
\hline $8 \%$ for 5 days (28\$/day) & 280 \\
\hline Costs saved by individuals (\$) & 860 \\
\hline Costs saved by avoiding work absence (\$) & 385 \\
\hline Cost of lost opportunity (1 Year) & 24640 \\
\hline Quality Adjusted Life Years (QALYs) (Benefits) & 26340 \\
\hline
\end{tabular}




\section{Conclusion}

A CBA for the costs as a result of sewer pipelines failure and health benefits that return on the community as a result of avoiding that failure was presented in this paper. CBA was used with the intent of determining the economic loss of sewer pipelines failure. Direct costs spent to reinstate the failed pipelines were defined as monetary amounts that can be distinctively shown in the bills of municipalities. While, indirect costs were defined as any costs borne by the society and/or environment as a result of that failure. These costs included: costs as a result of road closures and traffic diversion, additional consumption of fuel, additional running costs, costs for remediation of contaminated groundwater and soil, delays to work, loss of parking spaces and others. Avoiding the failure of sewer pipelines was considered as an enhancement for the quality of living as a result of better sanitation and avoiding costs spent in case of illnesses. A case study with real data was used to examine the applicability of the proposed method for a sewer pipeline in Montreal city. By calculating the different costs, it was found that the indirect costs represented a significant portion of the cost of failure which can't be neglected. It was concluded that as the benefit to cost ratio decreases the significance of failure increases indicating catastrophic levels of failure. There are several limitations and areas of enhancement for this research, such as adding other factors to be included in calculating the costs of failure. Also, other concepts could be included in the CBA such as the willingness to pay and acceptance. In addition, several enhancements in calculating the disruption distance and contaminated groundwater and soil volumes are also recommended.

This publication was made possible by NPRP grant \# (NPRP6-357-2-150) from the Qatar National Research Fund (a member of The Qatar Foundation). The statements made herein are solely the responsibility of the authors. Also the authors would like to thank the public works authority of Qatar (ASHGAL) for their support in the data collection.

\section{References}

1. Gaewski, P., Tata and Howard, Inc., and Blaha,F., AwwaRF, Analysis of Total Cost of Large Diameter Pipe Failures (2007).

2. Jones, C.. Paper presented at the Life Extension of Technologies Workshop, New York, Incentives and Barriers to the use of Trenchless Technology (1999)

3. Allouche, E., Ariaratnam, S., and AbouRizk, S. Construction Congress VI: ASCE, VA. 543-553, Multi-Dimensional Utility Model for Selection of a Trenchless Construction Method (2000).

4. Gilchrist, A., and Allouche, E. N.. Tunnelling and underground space technology, 201, 89-104, Quantification of social costs associated with construction projects: state-ofthe-art review (2005).

5. Manuilova, A., Dormuth, D., and Vanier, D. National Research Center, Canada, MIIP Report: A Case Study of Use and External Components of Social Costs that are related to Municipal Infrastructure Rehabilitation, (2009).

6. Rahman, S., Vanier, D.J., and Newton, L. A. National Research Center, Canada, MIIP Report: Social Cost Considerations for Municipal Infrastructure Management. (2005)

7. Martin, T., Johnson, D., and Anschell, S. Proceeding, Leading Edge Conference on Strategic Asset Management, IWA, Lisbon, Portugal, Using historical repair data to create customized predictive failure curves for sewer pipe risk modeling.(2007). 
8. Torterotot, J. P., Sousa e Silva, D., Barbier, R., Werey, C., Pereira A., Konig, A., Montginoul, M., and Waechter V. IWA Publishing, CARE-S Computer Aided Rehabilitation of Sewer and Storm Water Networks.73-88, (2006).

9. Cromwell, J. E., and Pearson, N. AWWARF, Denver, Cost of infrastructure failure. (2002).

10. Salman, B. and Salem, O. Journal of pipeline systems engineering and practice, Risk Assessment of Wastewater Collection Lines Using Failure Models and Criticality Ratings., 3, 68-76. (2012)

11. Ana, E., V., Ph.D. dissertation, University of Brussels, Belgium. Sewer asset management - sewer structural deterioration modelling and multi-criteria decision making in sewer rehabilitation projects prioritization (2009).

12. Higgins, A.M. and Harris, A.H. Critical Care Clinics, Health economic methods: costminimization, cost-effectiveness, cost-utility, and cost-benefit evaluations, 281, 11-24.( 2012)

13. Polinder, S., Toet, H., Panneman, M. and Beeck, E. World Health Organization Regional Office for Europe, Denmark, Methodological Approaches for Costeffectiveness and Cost-utility Analysis of Injury Prevention Measures, (2011).

14. Moayyedi, P. and Mason, J. ,European Journal of Gastroenterology and Hepatology, Cost-utility and cost-benefit analyses: how did we get here and where are we going?, 16-6, 527-534 (2004).

15. Adey, B.T. and Hajdin, R. Journal of Structure and Infrastructure Engineering. Methodology for determination of financial needs of gradually deteriorating bridges with only structure level data, 7 -8, 645-660 (2011).

16. Vacheyroux, G. and Corotis, R., Journal of Structure and Infrastructure Engineering Strategies of investment in the management of urban bridges: a life-cycle approach illustrated for Paris, , 9-11, 1080-1093 (2013).

17. Marinoni, O., Adkins, P. and Hajkowicz, S. Journal of Environmental Modelling and Software, Water planning in a changing climate: join application of cost utility analysis and modern portfolio theory, 26 -1, 18-29 (2011).

18. Hajkowicz, S., Spencer, R., Higgins, A. and Marinoni, O., Journal of Environmental Management, Evaluating water quality investments using cost utility analysis, , 884, 1601-1610, (2008)

19. North American Electric Reliability Corporation, Standard CIP-002-1, Cyber Security, Critical Asset Identification. Washington, DC (2006).

20. European Commission, Proposal for a Directive of the Council on the Identification and Designation of European Critical Infrastructure and the Assessment of the Need to Improve Their Protection, COM2006787 Final, Brussels, Belgium (2006).

21. Khogali, W. E., and Mohamed, E. H. Managing utility cuts: Issues and considerations. Paper presented at the NCRR/CPWA Seminar Series: Innovations in Urban Infrastructure. APWA International Public Works Congress NRCC/CPWA Seminar Series Innovations in Urban Infrastructure, 1-11, (1999).

22. Gourvil, L. and Joubert, F. Évaluation de la congestion routièredans la région de Montréal: Québec: Transports Québec, (2004).

23. Boyce, G., and Bried, E., Proceedings of North American No-Dig, Benefit-cost analysis of micro-tunneling in an urban area. 94,36-01 (1994)

24. Pucker, J., Allouche, E., and Sterling, R. Proceeding of NASTT No-Dig Conference, Social Costs Associated with Trenchless Projects: Case Histories in North American and Europe. C4-04 (2006).

25. Zhang, A., Boardman, A. E., Gillen, D., and Waters, I., Report for Transport Canada Towards estimating the social and environmental costs of transportation in Canada. (2004) 
26. Gulliver, J., Springer-Verlag New York, 10.1007/978-1-4614-5731-2, Transport and Fate of Chemicals in the Environment: Selected Entries from the Encyclopedia of Sustainability Science and Technology (2012).

27. Rail, D., Technomic Publishing Company, Inc., Lancaster, PA. Groundwater Contamination: Sources, Control, and Preventative Measures. 37-40, (1989)

28. World Bank, Urban Development Sector Unit, Vietnam Country Department of the World Bank, Project appraisal document on a proposed loan to the Socialist Republic of Vietnam for the Ho Chi Minh City environmental sanitation project, (2001).

29. http://www.statcan.gc.ca/eng/start, accessed 15 November 2016 